\title{
How healthy is the healthspan concept?
}

\author{
Matt Kaeberlein (1D
}

Received: 16 July 2018 / Accepted: 24 July 2018/Published online: 6 August 2018

(C) American Aging Association 2018

\section{Challenges in defining healthspan}

The concept of healthspan is relatively new in geroscience research, which seeks to understand the biological mechanisms of aging (Burch et al. 2014; Sierra and Kohanski 2017). Prior to the year 2000, only 14 papers were indexed on PubMed with "healthspan" or "health span" in the title or abstract. By mid-2018, that number has grown to more than 900 (Fig. 1). Notably, several of these use the exact phrases "increases healthspan," "improves healthspan," or "extends healthspan," implying that healthspan is a quantifiable phenotype. In contrast, a recent discussion session at the 2018 Nathan Shock Center Summit and American Aging Association Annual Meeting entitled "How healthy is the healthspan concept?" indicates that there are no accepted or validated metrics for measuring healthspan. How then are claims of increased healthspan so routinely making it into the peer-reviewed literature? A widespread lack of clarity and precision in the use and meaning of this term among both authors and reviewers is evident, and this author will somewhat shamefacedly admit to being among the offenders (Bitto et al. 2016; Leiser et al. 2011; Sutphin et al. 2012; Urfer et al. 2017).

It is perhaps useful to begin by asking "what is the definition of healthspan?". While it is unlikely everyone would agree on a single definition, one common

M. Kaeberlein $(\square)$

Department of Pathology, University of Washington School of Medicine, Seattle, WA 98195, USA

e-mail: kaeber@uw.edu definition is that healthspan is the period of life spent in good health, free from the chronic diseases and disabilities of aging. This definition implies that healthspan is a length of chronological time beginning at birth and ending at some subsequent time when an individual is no longer in good health and/or is suffering from diseases or disabilities of aging. Conceptually, this is a nice definition, as it allows us to consider healthspan as a quantitative continuous variable, in the same way that we consider lifespan. This would, in principle, be useful for determining how different genes, environmental parameters, or interventions impact healthspan in a quantitative way. It would also allow us to measure the relative impact of such factors on healthspan compared to their impact on lifespan. This is important, since some interventions have been suggested to increase healthspan without increasing lifespan, and such interventions would have clinical utility if they had similar health benefits in people. Similarly, it is at least theoretically possible that other interventions could increase lifespan without increasing healthspan to a proportional or greater extent, which is something we clearly do not want to do in people.

It is immediately apparent, however, that there are some significant problems with this definition of healthspan. First, "good health" is subjective. Two different people with the same medical condition may perceive their health quite differently. Additionally, "good health" may also be reversible, with some individuals going through multiple periods of poor health interspersed with good health. It is also unclear how many diseases and/or disabilities an individual must 


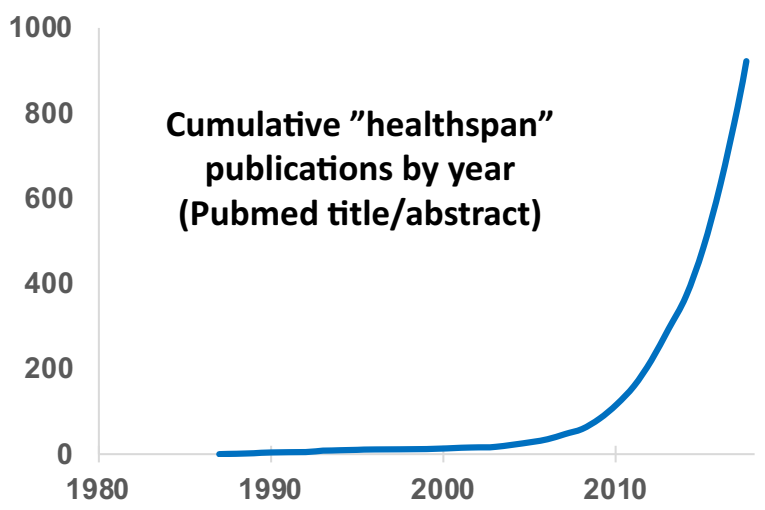

Fig. 1 Dramatic increase in use of the word "healthspan" in biomedical literature. The cumulative number of Pubmed indexed articles annotated with "healthspan" or "health span" in the title or abstract is shown by year. A total of 929 articles were returned. Date of search: July 15, 2018

have to reach the end of their healthspan. Is one disease enough? Are all diseases equal in this regard? Finally, it is not the case that only diseases of aging cause loss of good health. There are many severe childhood disorders, for example, that result in sufficiently poor health that they would likely constitute an end of that individual's healthspan by any reasonable definition.

One major flaw with the current healthspan concept is that health is not a binary trait with only two states: good and bad. Instead, health itself may be better considered as a continuous variable that changes in a dynamic way throughout life. The health trajectory will be different in different individuals, but will generally trend downward with age. In principle, a "healthspan index" which quantifies overall health could be developed, perhaps akin to established frailty indices (Kane et al. 2017; Kim et al. 2017; Mitnitski et al. 2017) or geropathology platforms (Snider et al. 2018), but more inclusive of other aspects of health (e.g. emotional, psychological, etc.). With such a tool, it would certainly be possible to arbitrarily define a value below which healthspan is considered to be over if a discreet chronological measure of healthspan is required. More informative perhaps would be to consider the area under the healthspan curve over a given time period or throughout life, in order to obtain a single "healthspan metric" for each individual (Fig. 2). Such a metric would allow for rigorous, statistically valid comparisons of geroscience interventions to determine their impact on healthspan.

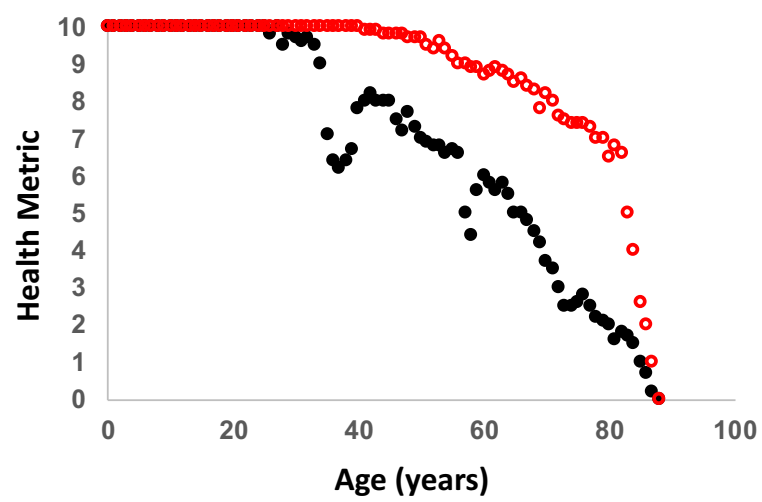

Fig. 2 Hypothetical "healthspan metric" curves. Idealized example of data that could be obtained for two individuals who are assessed for a standardized healthspan metric (defined on a 10point scale) annually over their entire lives. Individual no. 1 (black filled circles) illustrates the potential for declining health followed by recovery around age 36 and again around age 57 . Individual no. 2 (red open circles) illustrates someone who is exceptionally healthy until near the very end of life. By calculating the area under each curve, a single "healthspan metric" can be obtained. Individual no. 1 has a lifetime healthspan value of 610 compared to individual no. 2 with a lifetime healthspan value of 796 . Both individuals have a lifespan of 87 years

\section{When and where to use the term "healthspan"}

Until such time as a comprehensive healthspan metric is adopted, it would seem prudent to refrain from using the term "healthspan" in the scientific literature, except as a conceptual construct. While this may seem an extreme position, a reasoned argument can be made that the status quo is detrimental, sowing confusion within the field and perhaps giving the impression that geroscience is less rigorous than other fields of scientific research.

Particularly problematic are studies that measure only one or two age-related phenotypes and make claims regarding healthspan in general. It was recently suggested that an "overall assessment of health in several domains across several ages" should be required to justify claims that an intervention increases healthspan (Richardson et al. 2016); however, this recommendation does not address the fundamental problems outlined above. Even in cases where an intervention appears to broadly delay age-related declines and improve functional measures of aging "in several domains and across several ages", such as rapamycin treatment in mice (An et al. 2017; Johnson et al. 2015), there is no method available to assess whether healthspan is extended in a 
statistically valid manner. Indeed, imprecise definitions of healthspan have likely contributed to controversies related to rapamycin in mice (Johnson et al. 2013; Neff et al. 2013; Richardson 2013) and mutation of the insulin-like receptor DAF-2 in C. elegans (Bansal et al. 2015; Ewald et al. 2018; Hahm et al. 2015). Given the current inability to quantify healthspan at all, these would seem to be counterproductive debates with potentially negative impact on how the field is perceived.

The concept of healthspan has proven to be quite useful, on the other hand, for popularizing geroscience among the broader scientific and lay communities. It is a concept that is easy to understand and is more palatable to a general audience than increasing lifespan. Indeed, while some would debate the ethics of research aimed at increasing lifespan (Pijnenburg and Leget 2007), there is broad agreement that expanding the period of life spent in good health is a worthwhile research endeavor, with significant economic and social benefits (Goldman et al. 2013; Nikolich-Zugich et al. 2016). As such, the concept of improving healthspan should continue to be an outward-facing point of emphasis for geroscience in the future.

Acknowledgements The author would like to acknowledge the speakers in the "How Healthy is the Healthspan Concept" session at the 2018 Nathan Shock Center Symposium and American Aging Association Annual Meeting. MK is co-director of the University of Washington Nathan Shock Center of Excellence in the Basic Biology of Aging. NIH P30AG013280.

\section{References}

An JY, Quarles EK, Mekvanich S, Kang A, Liu A, Santos D, Miller RA, Rabinovitch PS, Cox TC, Kaeberlein M (2017) Rapamycin treatment attenuates age-associated periodontitis in mice. Geroscience 39:457-463. https://doi.org/10.1007 /s11357-017-9994-6

Bansal A, Zhu LJ, Yen K, Tissenbaum HA (2015) Uncoupling lifespan and healthspan in Caenorhabditis elegans longevity mutants. Proc Natl Acad Sci U S A 112:E277-E286. https://doi.org/10.1073/pnas.1412192112

Bitto A, Ito TK, Pineda VV, LeTexier NJ, Huang HZ, Sutlief E, Tung H, Vizzini N, Chen B, Smith K, Meza D, Yajima M, Beyer RP, Kerr KF, Davis DJ, Gillespie CH, Snyder JM, Treuting PM, Kaeberlein M (2016) Transient rapamycin treatment can increase lifespan and healthspan in middle- aged mice. eLife 5:e16351. https://doi.org/10.7554 /eLife. 16351

Burch JB, Augustine AD, Frieden LA, Hadley E, Howcroft TK, Johnson R, Khalsa PS, Kohanski RA, Li XL, Macchiarini F, Niederehe G, Oh YS, Pawlyk AC, Rodriguez H, Rowland JH, Shen GL, Sierra F, Wise BC (2014) Advances in geroscience: impact on healthspan and chronic disease. J Gerontol A Biol Sci Med Sci 69(Suppl 1):S1-S3. https://doi.org/10.1093/gerona/glu041

Ewald CY, Castillo-Quan JI, Blackwell TK (2018) Untangling longevity, Dauer, and healthspan in Caenorhabditis elegans insulin/IGF-1-signalling. Gerontology 64:96-104. https://doi.org/10.1159/000480504

Goldman DP, Cutler D, Rowe JW, Michaud PC, Sullivan J, Peneva D, Olshansky SJ (2013) Substantial health and economic returns from delayed aging may warrant a new focus for medical research. Health Aff 32:1698-1705. https://doi. org/10.1377/hlthaff.2013.0052

Hahm JH, Kim S, DiLoreto R, Shi C, Lee SJ, Murphy CT, Nam HG (2015) C. elegans maximum velocity correlates with healthspan and is maintained in worms with an insulin receptor mutation. Nat Commun 6:8919. https://doi. org/10.1038/ncomms9919

Johnson SC, Martin GM, Rabinovitch PS, Kaeberlein M (2013) Preserving youth: does rapamycin deliver? Sci Transl Med 5: 211 fs240. https://doi.org/10.1126/scitranslmed.3007316

Johnson SC, Sangesland M, Kaeberlein M, Rabinovitch PS (2015) Modulating mTOR in aging and health. Interdiscip Top Gerontol 40:107-127. https://doi.org/10.1159/000364974

Kane AE, Gregson E, Theou O, Rockwood K, Howlett SE (2017) The association between frailty, the metabolic syndrome, and mortality over the lifespan. Geroscience 39:221-229. https://doi.org/10.1007/s11357-017-9967-9

Kim S, Myers L, Wyckoff J, Cherry KE, Jazwinski SM (2017) The frailty index outperforms DNA methylation age and its derivatives as an indicator of biological age. Geroscience 39: 83-92. https://doi.org/10.1007/s11357-017-9960-3

Leiser SF, Begun A, Kaeberlein M (2011) HIF-1 modulates longevity and healthspan in a temperature-dependent manner. Aging Cell 10:318-326. https://doi.org/10.1111/j.14749726.2011.00672.x

Mitnitski AB, Rutenberg AD, Farrell S, Rockwood K (2017) Aging, frailty and complex networks. Biogerontology 18: 433-446. https://doi.org/10.1007/s10522-017-9684-x

Neff F, Flores-Dominguez D, Ryan DP, Horsch M, Schröder S, Adler T, Afonso LC, Aguilar-Pimentel JA, Becker L, Garrett L, Hans W, Hettich MM, Holtmeier R, Hölter SM, Moreth K, Prehn C, Puk O, Rácz I, Rathkolb B, Rozman J, Naton B, Ordemann R, Adamski J, Beckers J, Bekeredjian R, Busch DH, Ehninger G, Graw J, Höfler H, Klingenspor M, Klopstock T, Ollert M, Stypmann J, Wolf E, Wurst W, Zimmer A, Fuchs H, Gailus-Durner V, Hrabe de Angelis M, Ehninger D (2013) Rapamycin extends murine lifespan but has limited effects on aging. J Clin Invest 123:32723291. https://doi.org/10.1172/JCI67674

Nikolich-Zugich J et al (2016) Preparing for an aging world: engaging biogerontologists, geriatricians, and the society. $\mathrm{J}$ 
Gerontol A Biol Sci Med Sci 71:435-444. https://doi. org/10.1093/gerona/glv164

Pijnenburg MA, Leget C (2007) Who wants to live forever? Three arguments against extending the human lifespan. J Med Ethics 33:585-587. https://doi.org/10.1136/jme.2006.017822

Richardson A (2013) Rapamycin, anti-aging, and avoiding the fate of Tithonus. J Clin Invest 123:3204-3206

Richardson A, Fischer KE, Speakman JR, de Cabo R, Mitchell SJ, Peterson CA, Rabinovitch P, Chiao YA, Taffet G, Miller RA, Rentería RC, Bower J, Ingram DK, Ladiges WC, Ikeno Y, Sierra F, Austad SN (2016) Measures of healthspan as indices of aging in mice-a recommendation. J Gerontol A Biol Sci Med Sci 71:427-430. https://doi.org/10.1093/gerona/glv080

Sierra F, Kohanski R (2017) Geroscience and the trans-NIH Geroscience interest group. GSIG Geroscience 39:1-5. https://doi.org/10.1007/s11357-016-9954-6
Snider TA, Richardson A, Stoner JA, Deepa SS (2018) The Geropathology Grading Platform demonstrates that mice null for $\mathrm{Cu} / \mathrm{Zn}$-superoxide dismutase show accelerated biological aging. Geroscience 40:97-103. https://doi.org/10.1007 /s11357-018-0008-0

Sutphin GL, Bishop E, Yanos ME, Moller RM, Kaeberlein M (2012) Caffeine extends life span, improves healthspan, and delays age-associated pathology in Caenorhabditis elegans. Longev Healthspan 1:9. https://doi.org/10.1186/2046-2395-1-9

Urfer SR, Kaeberlein TL, Mailheau S, Bergman PJ, Creevy KE, Promislow DEL, Kaeberlein M (2017) A randomized controlled trial to establish effects of short-term rapamycin treatment in 24 middle-aged companion dogs. Geroscience 39:117-127. https://doi.org/10.1007/s11357017-9972-z 